\title{
Immediate effects of cervical unilateral anterior-posterior mobilisation on shoulder pain and impairment in post-operative arthroscopy patients
}

Jürg Hauswirth a, b, c, Markus J. Ernst b* Marianne Lanz Preusser b, d, André Meichtry b, Jan Kool b, e, Rebecca J. Crawford f,g

a. Cantonal Hospital of Baselland / Bruderholz, CH-4201 Bruderholz, Switzerland

b. Zurich University of Applied Sciences, Department of Health, Institute of Physiotherapy, CH-8401 Winterthur, Switzerland

c. International Maitland Teachers association (IMTA)

d. Schaffhausen Cantonal Hospital, Geissbergstrasse 81, CH-8208 Schaffhausen, Switzerland

e. Rehabilitation Centre Kliniken Valens CH-7317 Valens, Switzerland

f. Zurich University of Applied Sciences, Department of Health, Institute of Health Sciences, CH-8401 Winterthur, Switzerland

g. Curtin University, Faculty of Health Sciences, Perth, Australia

*Corresponding Author: Markus J. Ernst

Zurich University of Applied Sciences, Department of Health, Institute of Physiotherapy, Technikumstr. 71, CH-8401 Winterthur, Switzerland

Tel.: +4958934 6448, Fax: +4958935 6448,

E-mail: markus.ernst@zhaw.ch 


\section{Abstract \\ Background:}

Lateral gliding cervical spine mobilisation is shown to improve shoulder pain, disability and function. However, despite common clinical-use, no study reports the effect of unilateral anterior-posterior (A-P) cervical mobilisation on shoulder pain and function, and particularly in patients after arthroscopic shoulder surgery.

\section{Objective:}

Examine the immediate effect of single-level Grade III cervical unilateral A-P mobilisation on shoulder pain, flexion and abduction range of motion (ROM) and external rotator strength compared to placebo cervical unilateral A-P light touch pressure.

\section{Methods:}

Single session intervention with a crossover design in 32 (15 women) postoperative arthroscopic shoulder patients.

\section{Results:}

Immediate and superior treatment effects were shown for A-P cervical mobilisation in improving flexion ROM, isometric strength of external rotation, and pain intensity during flexion (all $p<0.05$ ) when compared to the placebo. However, effects may not be considered clinically meaningful.

\section{Conclusions:}

Unilateral A-P mobilisation applied to the cervical spine shows a tendency toward positively influencing post-arthroscopy shoulder pain and function. Further study examining cervical mobilisations directed in different planes to influence shoulder motion appear warranted.

\section{Keywords}

Shoulder arthroscopy, cervical spine mobilisation, pain, range of motion, isometric strength 


\section{Background}

Arthroscopic shoulder surgeries are common, particularly rotator cuff repairs and decompressions that have seen more than $200 \%$ and $700 \%$ increases in recent decades, respectively $[1,2]$. This popularity may in part relate to an ageing population whose disabling musculoskeletal disease is also rising [3]. Manual and exercise therapies are considered important for rehabilitating these patients, with the main focus of interventions being to restore shoulder range of motion (ROM) and muscle strength [4]. Assessing the role of adjacent joints in shoulder movement dysfunction is a clinically-reasoned practise, and includes examination of the cervical spine's active and passive ROM, which may then be integrated into management strategies $[5,6]$.

Beneficial therapeutic effects of cervical spine manual mobilisation techniques on pain, autonomic and motor function have been shown [7]. These effects are purportedly elicited by afferents in skin, muscle, joint, and neurovascular structures in response to the mechanical stimulus, producing centrally-mediated (especially periaqueductal grey) pain inhibition, reduced mechanosensitivity, either sympathetic excitation or inhibition, and either increased or decreased ROM [7-10]. Effects have been shown to extend remotely to influence the shoulder [11-13] and elbow [14-17]. In addition to intrinsic shoulder structures with causation for shoulder pain [18-20], extrinsic structures like the cervical $[11,12,21]$ and thoracic spines [22-25], and upper ribs [26] have been implicated.

Non-specific neck pain and cervical spine joint dysfunction negatively influence the duration of shoulder pathologies $[12,27]$. Consequently, treatments targeting the cervicothoracic spine are often integrated into manual therapy rehabilitation of shoulder problems [5, 28, 29]. This has been rationalised on the basis of the mobilisation activating mechanoreceptors and proprioceptors of targeted tissues and thereby optimizing neuromuscular function of the upper extremity [11, 30, 31]. Physiological and accessory cervical mobilisations can be 
undertaken in multiple directions [32], with the most commonly used involving sagittal (posterior-anterior, and anterior-posterior (A-P)), coronal (lateral/transverse), and axial (rotation) planes [28, 32].

Improvement of shoulder function has been shown in applying cervical mobilisation directed to facilitate physiological coronal plane motion [11-13]. These lateral (or transverse) glide mobilisations at the lower cervical segments provided short-term improvement to pain, ROM and external rotation strength in patients with insidious painful shoulders [13], patients with a painful arc during abduction [12], and in neck patients with concomitant shoulder muscle weakness [11]. In contrast, unilateral posterior-anterior mobilisations have not shown significant improvements in shoulder impingement patients [21]. As far as we are aware, no studies have examined the influence of A-P cervical mobilisations for shoulder problems, despite their common use in clinic [32]. A-P mobilisations are particularly employed for painful syndromes presenting in the anterior shoulder where their neurophysiological influence has been demonstrated, and as compared to P-A mobilisations for posteriorly presenting neck and shoulder pain [32, 33]. Further, the effect of cervical mobilisation on outcomes after shoulder arthroscopy has not been described. Our study therefore aimed to investigate a discreet and commonly-used cervical mobilisation technique on a series of patients referred for shoulder rehabilitation after arthroscopic surgery.

\section{Objective}

Examine the immediate effect of unilateral Grade III A-P cervical mobilisation on shoulder pain and function when compared with a unilateral cervical A-P light touch pressure applied at the same level.

\section{Methods}


Participants were consecutively recruited at outpatient orthopedic physiotherapy departments of two general hospitals subsequent to referral by their surgeon (differed according to hospital) for physiotherapy rehabilitation. Patients had undergone arthroscopic shoulder surgery including acromioplasty, rotator cuff repair or bursectomy surgeries within six months. All participants were cleared by their surgeon for active movement and isometric external rotation. Exclusion criteria included: Shoulder rheumatoid and/or osteoarthritis, cortisone injections in the previous month, past symptomatic neck trauma or surgery, cervical radiculopathy, peripheral nerve lesions, and general contraindications for cervical manual therapy including metastases, spinal cord or cauda equina signs, osteoporosis, vertebrobasilar insufficiency, and unstable cervical spine spondylolisthesis. Baseline severity of patients' symptoms and disability were measured by using the Disability of the Arm, Shoulder and Hand questionnaire (DASH) where scores ranging from 0 (no symptoms and disability) to 100 (maximum symptoms and disability) [34, 35]. Presence of pre-operative non-specific cervical complaints was additionally recorded.

\section{Treatment procedures}

The order of applying treatment (Rx) and placebo (Pla) interventions to each participant was randomized for this single-session cross-over study.

The Rx included Grade III oscillatory unilateral A-P mobilization applied for 3 minutes to the cervical spine at the most symptomatic, adjacent segment (when applicable), and side according to the Maitland concept $[32,36]$. Symptomatic segment was defined as the one most associated with shoulder pain, caused local pain, and/or showed the greatest restriction to passive accessory A-P segmental motion [32, 36, 37]. When necessary, more than one segment was treated if the physiotherapist considered a multi-level contribution existed. The intervention used as placebo (Pla) included maintained light touch (Grade I) applied to the same cervical location for 3 minutes but without pressure or motion into resistance. Rx and Pla were applied with the patient lying supine with a towel placed under the head to ensure a horizontal and comfortable neck position. Upper limbs were supported by a pillow under the 
elbow if necessary in achieving a pain-free and comfortable resting position. Interventions were undertaken in a physiotherapy practice, by two experienced manual therapists (14 (author $\mathrm{JH}$ ) and 20 (author MLP) years) specialized in the Maitland concept; both therapists had a priori knowledge of the study and practiced and agreed to the treatment techniques. According to routine practice, participants were informed that local tenderness may be experienced after the session.

\section{Outcomes}

Outcome measures were assessed immediately before, between Rx and Pla interventions, and after both interventions, and included shoulder ROM in flexion and abduction using photographs [12], pain severity using the numeric rating scale (NRS) [38], and external rotation strength using the Isobex device (MDS AG, Switzerland) [39], each according to established methods.

ROM was assessed in standing against a white wall and using photographic documentation according to the method described by McClatchie et al. [12]. Markers were placed at: centero-lateral thorax, one thumb-width distal to the dorsal acromial angle, and the olecranon process to measure flexion (Figure 1a), and at the jugular fossa, coracoid process, and one thumb width lateral to the medial epicondyle, to measure abduction (Figure 2a). Participants were asked to raise their arm twice in both flexion (F) and abduction (Abd) (separately) indicating their initial onset of pain (P1) and then their maximal achievable active range as limited by either pain or their end of range (EOR). Attending therapists controlled for correct movement performance within each plane; photographs were taken at each position; ROM was measured from the photographs by an independent rater connecting marker positions with a line (Figure $1 \mathrm{~b}$ and $2 \mathrm{~b}$ ) and by using a commercially available protractor. Four measurements were derived: F-P1, F-EOR, Abd-P1, and Abd-EOR, and were recorded to the nearest degree as the smallest measure available; change $\geq 5^{\circ}$ was considered clinically meaningful improvement $[40,41]$. Intra-rater reliability for this method was determined by repeat measures three days apart of abduction and flexion EOR for ten randomly-selected 
subjects' images. Photographs were presented to the rater in random order and without connecting lines between markers.

Shoulder pain was assessed at each time-point with the NRS at flexion and abduction EOR, where 0 equated to no pain and 10 reflected the most severe pain imaginable [38]. Two measurements at the EOR were taken: Pain-Abd-EOR, Pain-F-EOR; a 2-point reduction of pain was considered clinically meaningful [42].

Isometric external rotation strength was examined in upright sitting with the upper arm by the side and elbow at $90^{\circ}$ flexion and with the Isobex positioned at the wrist. Patients were instructed to perform maximum isometric external rotation at the shoulder by slowly pushing the wrist against the sling until they felt pain (Figure 2); the peak strength (kilogram force; kgf) was recorded (Strength-ER) [39]. The mean of three consecutive measurements was calculated; a 10\% change between measurement time points was considered clinically meaningful [43].

The study was registered and approved by the regional ethics board. All patients received verbal and written information about the study and gave their signed informed consent prior to enrollment.

\section{Data analysis}

A linear mixed regression model was employed to analyse the seven outcome variables for: treatment (Rx versus $\mathrm{Pla}$ ), period (first versus second) and treatment-period interaction (sequence) as fixed effects and subject as a random intercept. In the model, we controlled for pre-operative cervical complaints. Model assumptions were tested by analysis of residuals. The effects of sequence and presence of pre-operative cervical complaints were not significant for all outcomes and were therefore removed from the final model. [44]. Reliability was examined with Intra-class correlation coefficients for a single random rater $\left(\mathrm{ICC}_{2,1}\right)$. All analyses were performed using the $\mathrm{R}$ statistical software $\mathrm{R}$ version 3.2.3 [45]. 


\section{Results}

Forty-four consecutive patients were screened for eligibility, with 32 (15 female; mean age $57 \pm 13$ years) entering the study. Patients had a mean DASH-Score of $45 \pm 18$ points indicating moderate group pain and disability with the potential for clinically meaningful change. Seventeen received the intervention first followed by the placebo (Rx-Pla), and 15 in the reverse order (Pla-Rx). Fourteen patients were treated symptomatically at a single cervical level and 18 at two levels. C5/6 was the most frequently treated segment $(n=21)$, followed by C6/7 ( $n=14), C 4 / 5(n=12), C 3 / 4(n=2)$, and C7/T1 $(n=1)$.

Significant treatment effects in favour of Rx were shown for F-EOR $\left(1.4^{\circ}, 95 \%\right.$ Confidence Interval $(\mathrm{Cl})=0.1$ to $\left.2.7^{\circ}, \mathrm{t}=2.07, \mathrm{p}<0.05\right)$, Pain- $\mathrm{F}(-0.5, \mathrm{Cl}=-0.9$ to $0.0, \mathrm{t}=-2.11, \mathrm{p}=0.04)$ and strength-ER $(0.2 \mathrm{kgf}, \mathrm{Cl}=0.0$ to $0.4 \mathrm{kgf}, \mathrm{t}=2.18, \mathrm{p}=0.04)$. A trend for treatment effect was shown for $\mathrm{F}-\mathrm{P} 1\left(4.3^{\circ}, \mathrm{Cl}=-0.6\right.$ to $\left.9.2^{\circ}, \mathrm{t}=1.73, \mathrm{p}=0.09\right)$. No other significant treatment effects were shown. Larger increases to ROM were shown after the second intervention period irrespective of the sequence indicating significant period effects for F-EOR $\left(1.4^{\circ}, \mathrm{Cl}=\right.$ 0.1 to $\left.2.7^{\circ}, t=2.07, p<0.05\right)$ and F-P1 $\left(6.0^{\circ}, \mathrm{Cl}=1.1\right.$ to $\left.10.9^{\circ}, t=2.39, p=0.02\right)$. No other period effects were shown. Period and treatment effects for all outcome variables are presented in Table 1; Table 2 additionally presents all effects ordered for group and measurement time points.

Perfect and excellent intra-rater reliability $(\mathrm{ICC} ; \mathrm{Cl})$ of the ROM photographs rating has been shown for flexion $(1.0 ; 1.0-1.0)$ and abduction $(0.95 ; 0.80-0.99)$, respectively.

\section{Discussion}

The current study investigated immediate effects of cervical A-P mobilisation in a single therapeutic session on active shoulder range of motion in flexion and abduction, pain intensity at EOR, and isometric external rotation strength in patients who had recently undergone shoulder arthroscopic surgery. We showed improvements in shoulder flexion ROM, reduced pain at end-range flexion, and increased external rotation strength in favour of 
the intervention. Despite the statistically significant improvements shown, only flexion range at first onset of pain $\left(6^{\circ}\right)$ after both interventions was considered clinically meaningful [42, 46]. However, our results are an encouraging indication that cervical A-P mobilisation has the potential to improve pain and ROM in shoulder flexion particularly, and also for external rotation strength, at least in the short term. As such, further investigation examining the potential for a cumulative effect after treatments applied over a longer time-period, and in relation to sustained patient response, appears warranted.

The effects of manual therapy interventions on local or remote sites are predominantly based on a neurophysiological mechanism. Peripheral and central pain modulations have been shown to be responsible for pain inhibition and improved motor function, which is arguably predominantly secondary to reduced mechanosensitivity [10, 30, 31]. Our finding showing improvements in shoulder flexion range and pain, but not abduction, is an interesting one and may be best rationalised within the "model of regional interdependence" proposed by Bialosky et al.[31]. Within that model, a biomechanical stimulus towards a joint purportedly has biomechanical and neurophysiological effects, even remotely [31]. We speculate that in addition to cervical joint effects, an A-P mobilisation of the cervical spine influences tension of the scalenes and other cervical muscles, thereby facilitating the cervicothoracic sagittal plane motion that enables shoulder flexion. In addition, the probable sympathetic response of increased skin conductance to the upper limb may also contribute to facilitating muscle activity $[7,8,10]$.

Investigating a different sagittal plane mobilisation technique, Cook et al. used standardized P-A mobilisation of the cervical spine for three sets of 30 seconds applied to either the stiffest or the lower two cervical segments in patients with shoulder impingement symptoms. They applied the cervical mobilisations as an adjunct to shoulder treatment, versus shoulder treatment alone, and could not demonstrate additional effects of the cervical mobilisation in relation to pain and disability. However, they did not examine either shoulder flexion or abduction ROM and therefore comparison to our study is limited. 
Lateral glide cervical mobilisation techniques have been successfully used in the treatment of shoulder dysfunction [11-13] and appear most effective for outcomes including pain, ROM $[12,13]$, and general perceived recovery [13]. While improvements to shoulder flexion [13] and abduction [12] have been described, Mintken et al. used no control intervention in their study examining flexion [13], and McClatchie et al. only measured abduction ROM [12] thereby limiting comparisons with each other and the present study. However, based on the biomechanical rationale where we propose that A-P cervical mobilisation facilitates shoulder sagittal plane motion (flexion), it seems reasonable that cervical lateral glide mobilisations facilitate shoulder abduction as McClatchie et al. describe [12]. That Mintken et al. showed improved shoulder sagittal motion might be explained by their additional use of thrust manipulations to the thoracic spine [13].

Studies, using single or short interventions to the thoracic spine and the upper ribs show conflicting immediate- $[22-24,26]$ and short-term results $[13,25]$ in patients with shoulder pathology. Thrust manipulation techniques seemed to show immediate effect in studies not using a control intervention, $[13,22,25,26]$, but were not superior when compared to sham manipulation $[23,24]$. Of these studies, only Mintken et al. examined pain and shoulder ROM as outcomes. The immediate group effect of approximately $20^{\circ}$ improved shoulder flexion shown by Mintken et al. cannot be attributed to one intervention given they jointly employed thoracic thrust manipulation and cervical lateral glides [13]. Haik et al. examined pain intensity and scapula kinematics during shoulder flexion in fifty subjects with shoulder impingement signs. Thrust manipulations resulted in improved scapula upward rotation during flexion when compared with placebo manipulation, however this effect was not considered clinically meaningful; they did not examine ROM at EOR [23]. No other study used ROM or strength measurements as an outcome, which limits further comparisons to our study.

The most symptomatic and adjacent cervical segments in terms of pain and resistance to passive accessory movements were treated in our study, and were predominantly C5/6 and 
its supra- and infra-adjacent levels. This approach of examining and treating comparable signs is supported by Cook et al. who found fair to moderate relationships between subjective complaints and objective comparable signs in neck and back pain patients [37]. Although assessing segmental mobility by movement palpation techniques has been criticised for poor specificity [47], it has, in combination with pain provocation during palpation, been shown to be reliable [48]. Wang et al. used a similarly localised approach to ours by including only patients with segment signs at C5, and to which a lateral glide mobilisation technique was subsequently targeted [11]. Targeting specific spinal levels has however been questioned by Aquino et al. who showed no differences in pain intensity when accessory Maitland techniques were applied to symptomatic or asymptomatic segments within the cervical spine. [49]. It is generally accepted clinically that most techniques cannot isolate to a single segment and motion adjacent to the application occur. However, the segment to which the intervention is primarily applied is reported to receive the greatest effect [32].

Results of our study should be considered in light of the following limitations. First, it may be argued that the applied intervention was too short to fully benefit from the mobilisation technique employed, which may be better cumulatively applied over consecutive sessions. While we acknowledge that this may be true, and as yet not adequately tested, we are encouraged by the immediate effects of this single-session intervention, particularly for the pain-free range of flexion. In support of this rationale, Cook et al. used P-A mobilisation in shoulder impingement patients and regarded their approach at risk for being sub-therapeutic despite providing 9-10 treatment sessions [21]. The question remains regarding how many treatments is optimum? Our speculation that cervical mobilisations applied in the same motion plane to that which shoulder ROM is requiring improvement, should therefore be investigated on a mechanistic basis and using cumulative treatments. Second, A-P cervical mobilisation may not be the most appropriate technique for every subject. By our own rationale we might expect better outcomes from A-P cervical techniques in shoulder patients with sagittal plane restrictions rather than those with limited abduction. A-P techniques are 
reported to be effective with anterior shoulder- or scapula pain [32, 33] and as a commonly utilised technique in clinics; this warrants further analysis. Third, our intervention used for placebo is a legitimate treatment under the Maitland concept and may arguably not have represented a reasonable placebo control [32]. However, we consider the selection the best choice for comparisons to a Grade III mobilisation where range of accessory motion and more substantial tissue pressure represent the most probable influences for neurophysiological and mechanistic treatment effect. Additionally, the positive effects of 'being touched' $[50,51]$ are accounted for. Fourth, the primary advantages of a crossover design are that smaller sample sizes are necessary, that subjects act as their own control, and that within-subject variability is generally assumed to be smaller than between-subject variability seen in parallel designs. However, a disadvantage is the potential for carry-over effects or permanent change from the first treatment that can be obscured. While we acknowledge this potential, our regression model showed no statistically significant carryover effect.

\section{Conclusion}

Unilateral anterior-posterior cervical mobilisation showed immediate improvement on shoulder flexion ROM and pain, and strength of isometric external rotation, but not on shoulder abduction in patients after shoulder arthroscopy. Our results are a promising example for involving the cervical spine in mechanically-reasoned assessment and manual treatment based on facilitating motion planes, in improving shoulder impairments after arthroscopic surgeries.

\section{Acknowledgments}

The authors thank all patients for participating in the study and Isabelle Werner for rating the measurements. 


\section{References}

[1] Ensor KL, Kwon YW, Dibeneditto MR, Zuckerman JD, Rokito AS. The Rising Incidence of Rotator Cuff Repairs. J Shoulder Elbow Surg. 2013;22(12):1628-32. 10.1016/j.jse.2013.01.006.

[2] Judge A, Murphy RJ, Maxwell R, Arden NK, Carr AJ. Temporal Trends and Geographical Variation in the Use of Subacromial Decompression and Rotator Cuff Repair of the Shoulder in England. The bone \& joint journal. 2014;96-B(1):70-4. 10.1302/0301-620X.96B1.32556.

[3] Vos T, Barber RM, Bell B, Bertozzi-Villa A, Biryukov S, Bolliger I, et al. Global, Regional, and National Incidence, Prevalence, and Years Lived with Disability for 301 Acute and Chronic Diseases and Injuries in 188 Countries, 1990-2013: A Systematic Analysis for the Global Burden of Disease Study 2013. Lancet. 2015. 10.1016/S0140-6736(15)60692-4.

[4] Ross D, Maerz T, Lynch J, Norris S, Baker K, Anderson K. Rehabilitation Following Arthroscopic Rotator Cuff Repair: A Review of Current Literature. J Am Acad Orthop Surg. 2014;22(1):1-9.

10.5435/JAAOS-22-01-1.

[5] Christensen N, Jones MA, Carr J. Clinical Reasoning in Orthopedic Manual Therapy. In: Grant R, editor. Physical Therapy of the Cervical and Thoracic Spine. 3rd. ed. New York: Churchill Livingstone; 2002. p. 85-104.

[6] Atkinson K, Coutts F, Hassenkamp AM. Physiotherapy in Orthopaedics: A Problem-Solving Approach: Elsevier/Churchill Livingstone; 2005.

[7] Sterling M, Jull G, Wright A. Cervical Mobilisation: Concurrent Effects on Pain, Sympathetic Nervous System Activity and Motor Activity. Man Ther. 2001;6(2):72-81. 10.1054/math.2000.0378.

[8] Chu J, Allen DD, Pawlowsky S, Smoot B. Peripheral Response to Cervical or Thoracic Spinal Manual Therapy: An Evidence-Based Review with Meta Analysis. J Man Manip Ther. 2014;22(4):220-9. 10.1179/2042618613Y.0000000062.

[9] Nijs J, de Kooning M, Beckwée D, Vaes P. The Neurophysiology of Pain and Pain Modulation: Modern Pain Neuroscience for Musculoskeletal Physiotherapists. In: Jull G, Moore A, Falla D, Lewis J, McCarthy C, Sterling M, editors. Grieve's Modern Musculoskeletal Physiotherapy. 4th ed. Edinburgh: Elsevier; 2014.

[10] Souvlis T, Vicenzino B, Wright A. Neurophysiological Effects of Spinal Manual Therapy. In: Boyling JD, Jull GA, editors. Grieve's Modern Manual Therapy. 3rd ed. Edinburgh: Churchill Livingstone; 2004. p. $367-80$.

[11] Wang SS, Meadows J. Immediate and Carryover Changes of C5-6 Joint Mobilization on Shoulder External Rotator Muscle Strength. J Manipulative Physiol Ther. 2010;33(2):102-8.

10.1016/j.jmpt.2009.12.006.

[12] McClatchie L, Laprade J, Martin S, Jaglal SB, Richardson D, Agur A. Mobilizations of the Asymptomatic Cervical Spine Can Reduce Signs of Shoulder Dysfunction in Adults. Manual Therapy. 2009;14(4):369-74. 10.1016/j.math.2008.05.006.

[13] Mintken PE, Cleland JA, Carpenter KJ, Bieniek ML, Keirns M, Whitman JM. Some Factors Predict Successful Short-Term Outcomes in Individuals with Shoulder Pain Receiving Cervicothoracic Manipulation: A Single-Arm Trial. Physical Therapy. 2010;90(1):26-42. 10.2522/ptj.20090095.

[14] Cleland JA, Whitman JA, Fritz JM. Effectiveness of Manual Physical Therapy to the Cervical Spine in the Management of Lateral Epicondylalgia: A Retrospective Analysis. Journal of Orthopaedic \& Sports Physical Therapy. 2004;34(11):713-22. 10.2519/jospt.2004.34.11.713.

[15] Fernandez-Camero J, Cleland JA, La Touche Arbizu R. Examination of Motor and Hypoalgesic Effects of Cervical Vs Thoracic Spine Manipulation in Patients with Lateral Epicondylalgia: A Clinical Trial. Journal of Manipulative and Physiological Therapeutics. 2011;34(7):432-40.

10.1016/j.jmpt.2011.05.019.

[16] Fernandez-Camero J, Fernandez-de-las-Penas C, Cleland JA. Immediate Hypoalgesic and Motor Effects after a Single Cervical Spine Manipulation in Subjects with Lateral Epicondylalgia. Journal of Manipulative and Physiological Therapeutics. 2008;31(9):675-81. 10.1016/j.jmpt.2008.10.005. 
[17] Slater H, Arendt-Nielsen L, Wright A, Graven-Nielsen T. Effects of a Manual Therapy Technique in Experimental Lateral Epicondylalgia. Manual Therapy. 2006;11(2):107-17.

10.1016/j.math.2005.04.005.

[18] van der Windt DA, Koes BW, de Jong BA, Bouter LM. Shoulder Disorders in General Practice: Incidence, Patient Characteristics, and Management. Ann Rheum Dis. 1995;54(12):959-64.

[19] Green S, Buchbinder R, Glazier R, Forbes A. Systematic Review of Randomised Controlled Trials of Interventions for Painful Shoulder: Selection Criteria, Outcome Assessment, and Efficacy. BMJ. 1998;316(7128):354-60.

[20] Cadogan A, Laslett M, Hing WA, McNair PJ, Coates MH. A Prospective Study of Shoulder Pain in Primary Care: Prevalence of Imaged Pathology and Response to Guided Diagnostic Blocks. BMC Musculoskelet Disord. 2011;12:119. 10.1186/1471-2474-12-119.

[21] Cook C, Learman K, Houghton S, Showalter C, O'Halloran B. The Addition of Cervical Unilateral Posterior-Anterior Mobilisation in the Treatment of Patients with Shoulder Impingement Syndrome: A Randomised Clinical Trial. Manual Therapy. 2014;19(1):18-24. 10.1016/j.math.2013.05.007. [22] Muth S, Barbe MF, Lauer R, McClure P. The Effects of Thoracic Spine Manipulation in Subjects with Signs of Rotator Cuff Tendinopathy. Journal of Orthopaedic \& Sports Physical Therapy. 2012;42(12):1005-16. 10.2519/jospt.2012.4142.

[23] Haik MN, Alburquerque-Sendin F, Silva CZ, Siqueira-Junior AL, Ribeiro IL, Camargo PR. Scapular Kinematics Pre- and Post-Thoracic Thrust Manipulation in Individuals with and without Shoulder Impingement Symptoms: A Randomized Controlled Study. Journal of Orthopaedic \& Sports Physical Therapy. 2014;44(7):475-87. 10.2519/jospt.2014.4760.

[24] Kardouni JR, Shaffer SW, Pidcoe PE, Finucane SD, Cheatham SA, Michener LA. Immediate Changes in Pressure Pain Sensitivity after Thoracic Spinal Manipulative Therapy in Patients with Subacromial Impingement Syndrome: A Randomized Controlled Study. Manual Therapy. 2015;20(4):540-6. 10.1016/j.math.2014.12.003.

[25] Boyles RE, Ritland BM, Miracle BM, Barclay DM, Faul MS, Moore JH, et al. The Short-Term Effects of Thoracic Spine Thrust Manipulation on Patients with Shoulder Impingement Syndrome. Man Ther. 2009;14(4):375-80. 10.1016/j.math.2008.05.005.

[26] Dunning J, Mourad F, Giovannico G, Maselli F, Perreault T, Fernandez-de-las-Penas C. Changes in Shoulder Pain and Disability after Thrust Manipulation in Subjects Presenting with Second and Third Rib Syndrome. Journal of Manipulative and Physiological Therapeutics. 2015;38(6):382-94.

10.1016/j.jmpt.2015.06.008.

[27] Kooijman MK, Barten DJ, Swinkels IC, Kuijpers T, de Bakker D, Koes BW, et al. Pain Intensity, Neck Pain and Longer Duration of Complaints Predict Poorer Outcome in Patients with Shoulder Pain - a Systematic Review. BMC Musculoskelet Disord. 2015;16(1):288. 10.1186/s12891-015-0738-4. [28] Haddick E. Management of a Patient with Shoulder Pain and Disability: A Manual Physical Therapy Approach Addressing Impairments of the Cervical Spine and Upper Limb Neural Tissue. Journal of Orthopaedic \& Sports Physical Therapy. 2007;37(6):342-50. 10.2519/jospt.2007.2458. [29] Yung E, Asavasopon S, Godges JJ. Screening for Head, Neck, and Shoulder Pathology in Patients with Upper Extremity Signs and Symptoms. Journal of Hand Therapy. 2010;23(2):173-85. 10.1016/j.jht.2009.11.004.

[30] Schmid A, Brunner F, Wright A, Bachmann LM. Paradigm Shift in Manual Therapy? Evidence for a Central Nervous System Component in the Response to Passive Cervical Joint Mobilisation. Manual Therapy. 2008;13(5):387-96. 10.1016/j.math.2007.12.007.

[31] Bialosky JE, Bishop MD, Price DD, Robinson ME, George SZ. The Mechanisms of Manual Therapy in the Treatment of Musculoskeletal Pain: A Comprehensive Model. Manual Therapy.

2009;14(5):531-8. 10.1016/j.math.2008.09.001.

[32] Hengeveld E, Banks K. Maitland's Vertebral Manipulation: Management of

Neuromusculoskeletal Disorders: Elsevier Health Sciences; 2013.

[33] Wells P. Cervical Dysfunction and Shoulder Problems. Physiotherapy. 1982;68(3):66-73.

[34] Hudak PL, Amadio PC, Bombardier C. Development of an Upper Extremity Outcome Measure: The Dash (Disabilities of the Arm, Shoulder and Hand) [Corrected]. The Upper Extremity Collaborative 
Group (Uecg). Am J Ind Med. 1996;29(6):602-8. 10.1002/(SICI)1097-0274(199606)29:6<602::AIDAJIM4>3.0.CO;2-L.

[35] Gummesson C, Atroshi I, Ekdahl C. The Disabilities of the Arm, Shoulder and Hand (Dash) Outcome Questionnaire: Longitudinal Construct Validity and Measuring Self-Rated Health Change after Surgery. BMC Musculoskelet Disord. 2003;4:11. 10.1186/1471-2474-4-11.

[36] Maitland GD. Neuro/Musculo-Skeletal Examination and Recording Guide. 5th ed. Glen Osmond, Australia: Lauderale Press; 1992.

[37] Cook C, Learman K, Showalter C, O'Halloran B. The Relationship between Chief Complaint and Comparable Sign in Patients with Spinal Pain: An Exploratory Study. Manual Therapy. 2015;20(3):4515. 10.1016/j.math.2014.11.007.

[38] Jensen MP, Karoly P, Braver S. The Measurement of Clinical Pain Intensity: A Comparison of Six Methods. Pain. 1986;27(1):117-26.

[39] Leggin BG, Neuman RM, lannotti JP, Williams GR, Thompson EC. Intrarater and Interrater Reliability of Three Isometric Dynamometers in Assessing Shoulder Strength. J Shoulder Elbow Surg. 1996;5(1):18-24. 10.1016/S1058-2746(96)80026-7.

[40] Mullaney MJ, McHugh MP, Johnson CP, Tyler TF. Reliability of Shoulder Range of Motion Comparing a Goniometer to a Digital Level. Physiotherapy theory and practice. 2010;26(5):327-33. 10.3109/09593980903094230.

[41] Kolber MJ, Vega F, Widmayer K, Cheng MS. The Reliability and Minimal Detectable Change of Shoulder Mobility Measurements Using a Digital Inclinometer. Physiotherapy theory and practice. 2011;27(2):176-84. 10.3109/09593985.2010.481011.

[42] Michener LA, Snyder AR, Leggin BG. Responsiveness of the Numeric Pain Rating Scale in Patients with Shoulder Pain and the Effect of Surgical Status. Journal of sport rehabilitation. 2011;20(1):11528.

[43] Bohannon RW. Reference Values for Extremity Muscle Strength Obtained by Hand-Held Dynamometry from Adults Aged 20 to 79 Years. Arch Phys Med Rehabil. 1997;78(1):26-32.

[44] Piantadosi S. Clinical Trials: A Methodological Perspective. 2nd. ed: John Wiley \& Sons Inc; 2005. [45] R Core Team. R: A Language and Environment for Statistical Computing. Vienna (Austria). 2015. [46] Muir SW, Corea CL, Beaupre L. Evaluating Change in Clinical Status: Reliability and Measures of Agreement for the Assessment of Glenohumeral Range of Motion. North American journal of sports physical therapy : NAJSPT. 2010;5(3):98-110.

[47] Stochkendahl MJ, Christensen HW, Hartvigsen J, Vach W, Haas M, Hestbaek L, et al. Manual Examination of the Spine: A Systematic Critical Literature Review of Reproducibility. J Manipulative Physiol Ther. 2006;29(6):475-85, 85 e1-10. 10.1016/j.jmpt.2006.06.011.

[48] Seffinger MA, Najm WI, Mishra SI, Adams A, Dickerson VM, Murphy LS, et al. Reliability of Spinal Palpation for Diagnosis of Back and Neck Pain: A Systematic Review of the Literature. Spine (Phila Pa 1976). 2004;29(19):E413-25. 10.1097/01.brs.0000141178.98157.8e.

[49] Aquino RL, Caires PM, Furtado FC, Loureiro AV, Ferreira PH, Ferreira ML. Applying Joint Mobilization at Different Cervical Vertebral Levels Does Not Influence Immediate Pain Reduction in Patients with Chronic Neck Pain: A Randomized Clinical Trial. J Man Manip Ther. 2009;17(2):95-100. 10.1179/106698109790824686.

[50] Chaibi A, Benth JS, Russell MB. Validation of Placebo in a Manual Therapy Randomized Controlled Trial. Scientific Reports. 2015;5. 10.1038/srep11774.

[51] Greene CS, Goddard G, Macaluso GM, Mauro G. Topical Review: Placebo Responses and Therapeutic Responses. How Are They Related? J Orofac Pain. 2009;23(2):93-107. 
Table 1: Treatment and Period effects for outcome variables $(n=32)$

\begin{tabular}{|c|c|c|c|c|c|c|c|}
\hline $\begin{array}{l}\text { Outcome } \\
\text { Variable }\end{array}$ & $\begin{array}{l}\text { Abd-EOR } \\
\left({ }^{\circ}\right)\end{array}$ & $\begin{array}{l}\text { Abd-P1 } \\
\left({ }^{\circ}\right)\end{array}$ & $\begin{array}{l}\text { F-EOR } \\
\left({ }^{\circ}\right)\end{array}$ & $\begin{array}{l}\text { F-P1 } \\
\left({ }^{\circ}\right)\end{array}$ & $\begin{array}{l}\text { Pain-Abd } \\
\text { (NRS) }\end{array}$ & $\begin{array}{l}\text { Pain-F } \\
\text { (NRS) }\end{array}$ & $\begin{array}{l}\text { strength- } \\
\text { ER (kgf) }\end{array}$ \\
\hline $\begin{array}{l}\text { Treatment effect } \\
\mathrm{Rx}-\mathrm{Pla} \\
(95 \% \mathrm{Cl})\end{array}$ & $\begin{array}{l}1.2 \\
(-2.0,4.3)\end{array}$ & $\begin{array}{l}0.3 \\
(-3.3,4.0)\end{array}$ & $\begin{array}{l}1.4 \\
(0.1,2.7)\end{array}$ & $\begin{array}{l}4.3 \\
(-0.6,9.2)\end{array}$ & $\begin{array}{l}-0.3 \\
(-0.6,0.1)\end{array}$ & $\begin{array}{l}-0.5 \\
(-0.9,0.0)\end{array}$ & $\begin{array}{l}0.2 \\
(0.0,0.4)\end{array}$ \\
\hline p-value & $p=0.47$ & $p=0.86$ & $p<0.05$ & $p=0.09$ & $p=0.11$ & $p=0.04$ & $p=0.04$ \\
\hline $\begin{array}{l}\text { Period effect } \\
\text { Period2 - Period1 } \\
(95 \% \mathrm{Cl})\end{array}$ & $\begin{array}{l}1.5 \\
(-1.7,4.6)\end{array}$ & $\begin{array}{l}3.0 \\
(-0.7,6.6)\end{array}$ & $\begin{array}{l}1.4 \\
(0.1,2.7)\end{array}$ & $\begin{array}{l}6.0 \\
(1.1,10.9)\end{array}$ & $\begin{array}{l}-0.1 \\
(-0.4,0.2)\end{array}$ & $\begin{array}{l}-0.3 \\
(-0.7,0.1)\end{array}$ & $\begin{array}{l}0.0 \\
(-0.2,0.2)\end{array}$ \\
\hline$p$-value & $p=0.37$ & $p=0.12$ & $p<0.05$ & $p=0.02$ & $p=0.62$ & $p=0.20$ & $p=0.79$ \\
\hline
\end{tabular}

$\mathrm{Abd}=$ abduction, $\mathrm{F}=$ flexion, $\mathrm{EOR}=$ end of range, $\mathrm{P} 1=$ pain onset, $\mathrm{ER}=$ external rotation, NRS= numeric rating scale, $\mathrm{Kgf}=$ kilogram force, $95 \% \mathrm{Cl}=95 \%$ Confidence interval with lower and upper interval limits presented.

Significant effects are presented in bold. 
Table 2 Treatment effects over three measurement time points and for both groups

\begin{tabular}{|c|c|c|c|c|c|c|c|}
\hline Sequence & $\begin{array}{l}\text { Abd- } \\
\text { EOR } \\
\left({ }^{\circ}\right)\end{array}$ & $\begin{array}{l}\text { Abd-P1 } \\
\left({ }^{\circ}\right)\end{array}$ & $\begin{array}{l}\text { F-EOR } \\
\left({ }^{\circ}\right)\end{array}$ & $\begin{array}{l}\text { F-P1 } \\
\left({ }^{\circ}\right)\end{array}$ & $\begin{array}{l}\text { Pain- } \\
\text { Abd } \\
\text { (NRS) }\end{array}$ & $\begin{array}{l}\text { Pain-F } \\
\text { (NRS) }\end{array}$ & $\begin{array}{l}\text { strength- } \\
\text { ER } \\
\text { (kgf) }\end{array}$ \\
\hline \multicolumn{8}{|l|}{ Baseline } \\
\hline RxPla & $58(24)$ & $39(15)$ & $104(23)$ & $80(25)$ & $4(2)$ & $4(2)$ & $3.2(1.3)$ \\
\hline PlaRx & $54(34)$ & $37(22)$ & $96(40)$ & $70(29)$ & $4(3)$ & $4(3)$ & $3.5(1.9)$ \\
\hline \multicolumn{8}{|l|}{ Period 1} \\
\hline RxPla & $68(27)$ & $47(20)$ & $106(22)$ & $85(27)$ & $4(2)$ & $4(2)$ & $3.8(1.9)$ \\
\hline PlaRx & $60(35)$ & $44(24)$ & $98(41)$ & $71(28)$ & $4(3)$ & $4(3)$ & $3.6(2.1)$ \\
\hline \multicolumn{8}{|l|}{ Period 2} \\
\hline RxPla & $68(27)$ & $50(20)$ & $106(22)$ & $87(26)$ & $4(2)$ & $4(2)$ & $3.5(1.9)$ \\
\hline PlaRx & $63(33)$ & $48(27)$ & 101(40) & $81(32)$ & $4(3)$ & $3(3)$ & $3.8(2.1)$ \\
\hline
\end{tabular}

$\mathrm{n}=32 \mathrm{Abd}=$ abduction, $\mathrm{F}=$ flexion, $\mathrm{EOR}=$ end of range, $\mathrm{P} 1=$ pain onset, $\mathrm{ER}=$ external rotation $\mathrm{NRS}=$ numeric rating scale, Kgf= kilogram force, RxPla=intervention first - placebo second,

PlaRx = placebo first - intervention second

Values are means (sd) 


\section{Figure captions}

Figure 1a: Marker set-up for flexion ROM

Figure 1b: ROM determination for flexion

Figure 2a: Marker set-up for abduction ROM

Figure 2b: ROM determination for abduction

Figure 3: Measurement of isometric shoulder external rotation strength

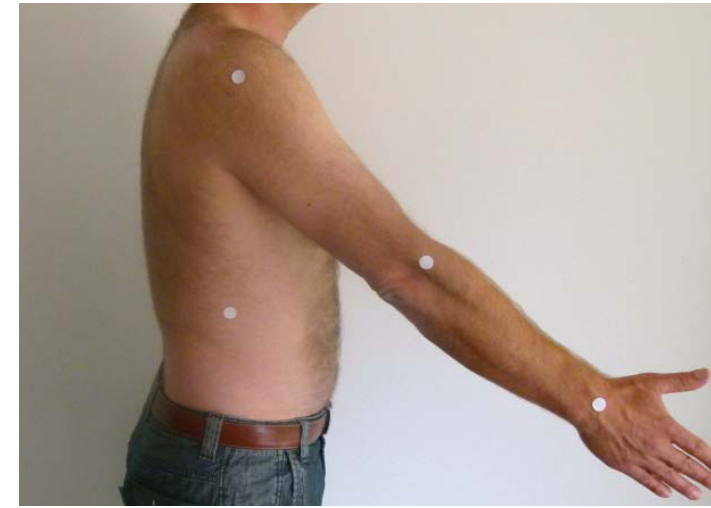

Figure 1a

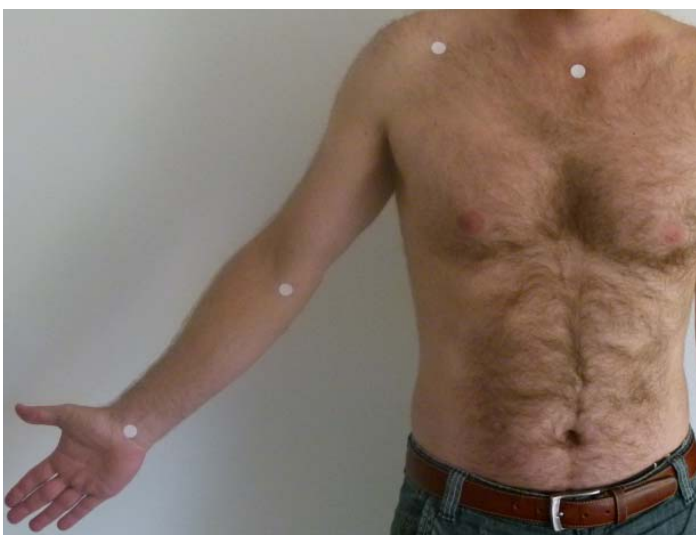

Figure $2 a$

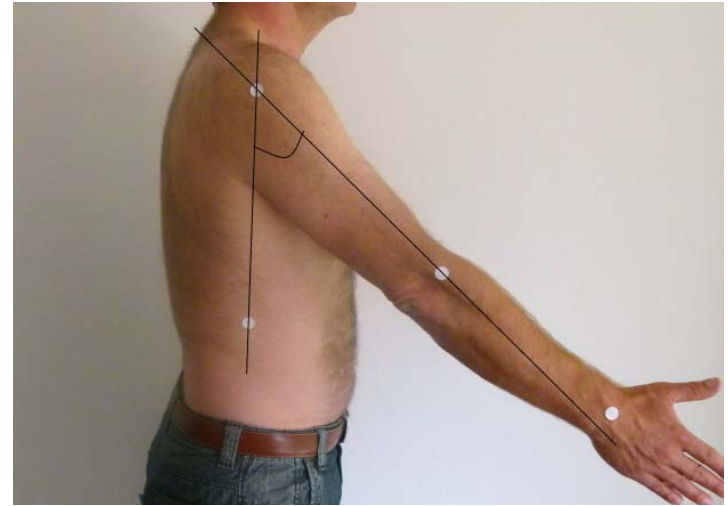

Figure 1b

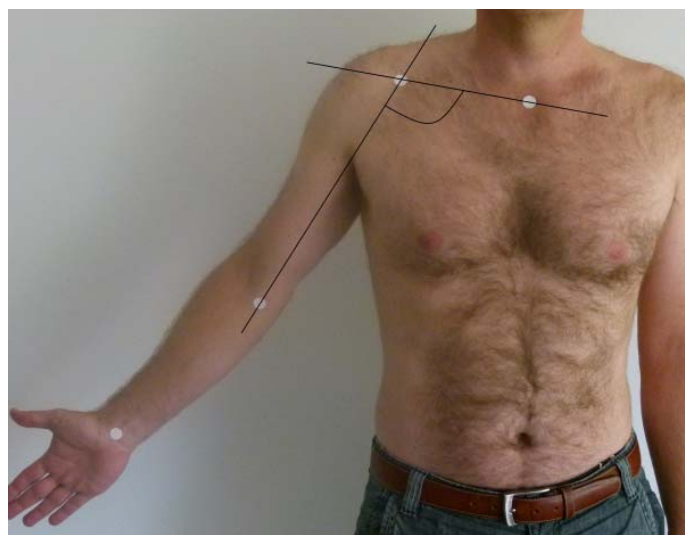

Figure 2b 


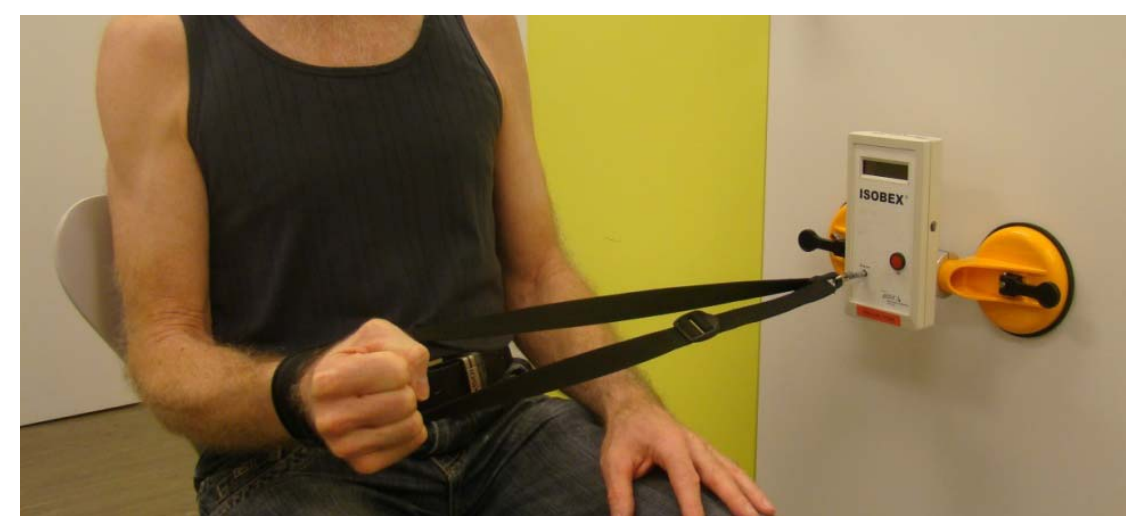

Figure 3 